\title{
Fatigue behaviour of a multiphase medium carbon steel: Comparison between ferrite/pearlite and tempered microstructures
}

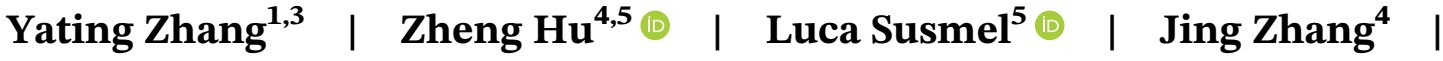 \\ Kun Zhang ${ }^{1,3}$ (1) | Yansen $\mathrm{Li}^{1,3}$ | Yang Wang ${ }^{1,3}$ () | Bingchen Wei,
}

${ }^{1}$ CAS Key Laboratory of Microgravity (National Microgravity Laboratory), Institute of Mechanics, Chinese Academy of Sciences, Beijing, 100190, China

${ }^{2}$ Center of Materials Science and Optoelectronics Engineering, University of Chinese Academy of Sciences, Beijing, 100049, China

${ }^{3}$ School of Engineering Science, University of Chinese Academy of Sciences, Beijing, 100049, China

${ }^{4}$ Science and Technology on Vehicle Transmission Laboratory, China North Vehicle Research Institute, Beijing, 100072, China

${ }^{5}$ Department of Civil and Structural Engineering, The University of Sheffield, Sheffield, S1 3JD, UK

\section{Correspondence}

Kun Zhang and Bingchen Wei, No.15 Beisihuanxi Road, Beijing, China (100190). Email: zhangkun@imech.ac.cn;

weibc@imech.ac.cn

\section{Funding information}

National Natural Science Foundation of China, Grant/Award Numbers: 51401028, 11402277, 11790292 and 51271193; Innovation Program, Grant/Award Number: 23709000000170004; Strategic Priority Research Program of the Chinese Academy of Sciences, Grant/Award Number: XDB22040303

\begin{abstract}
Fatigue crack growth is the essential process in the total life of components and is unavoidable in most structures and machines. In this study, the effects of cementite particles on the fatigue properties of medium carbon steel were investigated. A quenching and tempering treatment was developed to obtain uniformly distributed cementite particles with dozens of nanometres. To evaluate the fatigue properties, fatigue strength, fatigue crack growth rate and dynamic mechanical behaviour were examined. It was found that the fatigue strength of the tempered steel is much higher than that of air cooling ferrite/pearlite steel because the cementite particles act as barriers and hinder crack propagation during cyclic loading. More importantly, the high sensitivity of the damping peak to prior fatigue may play an important role on the fatigue history of multiphase medium carbon steel.
\end{abstract}

\section{K E Y W O R D S}

damping peak, fatigue crack growth, microstructure

\section{1 | INTRODUCTION}

Fatigue failure in metallic components and structures is a general technical problem, especially in vehicle gearings that are subjected to cyclic load. The pursuit of strength improvement and weight (or thickness) reduction, the improvement of fatigue strength, and fatigue crack growth (FCG) resistance of vehicle gearings, as well as the development of safety design, are strongly required to control fracture and assure the safety of structures. ${ }^{1-4}$ FCG is the essential process in the total life of components with notches and is unavoidable in most structures 
and machines. For example, friction plates in vehicle gearings are mainly fixed by spline teeth on a central shaft in the transmission, which produces large impact loads between spline teeth and creates torsional vibration. With the continuous development of vehicle power systems, increasingly more serious torsional vibration has appeared in the clutch, and it has become the dominant reason for fatigue failure. ${ }^{5}$

Fatigue strength can be improved by enhancing the strength of the material. ${ }^{6}$ To increase their toughness, the carbon level of multiphase medium carbon steels is reduced, and the decrease in strength is compensated by the addition of $\mathrm{Mn}$ and $\mathrm{Si}$. Quenching and tempering (QT) treatment is also a technique used to produce high strength and toughness with a tempered martensite microstructure. Extensive studies have been carried out to improve the fatigue strength of various steel grades through effective tempering processes. ${ }^{6-10}$ In conventional steels, air cooling (AC) from the forging temperature results in a ferrite/pearlite microstructure whose tensile properties and yield strength are inferior to those of QT steels. ${ }^{11-13}$ Numerous investigations have also been carried out to determine the effect of QT treatment on cementite precipitates. It is believed that the hard particles generally increase the flow stress and decrease the ductility and the fracture toughness of steel. ${ }^{14}$ However, the particles effect on fatigue behaviour and crack propagation mechanisms are not well documented.

Investigations on damage and fracture of materials from a micromechanics viewpoint may deepen our understanding on the nature of complex material behaviour under various conditions and provide a theoretical basis for improving their mechanical properties. Therefore, more and more attention is paid to the micro-failure theory nowadays. Many phenomenological and micromechanical models of ductile metal materials, brittle or quasi-brittle solids, and composites have been developed. ${ }^{15}$ The nature and the mechanism for very-highcycle fatigue of metallic material were also studied. ${ }^{16}$

In this study, the fatigue behaviours and dynamic mechanical properties of a typical multiphase medium carbon steel with different microstructures (ferrite/pearlite, tempered microstructures) are studied. Fatigue crack initiation and propagation mechanisms corresponding to different microstructural conditions are compared.

\section{2 | EXPERIMENTAL METHODS}

Medium carbon steel billets of $30 \mathrm{CrMnSiA}$ were prepared via two routes: one was heat treated for $40 \mathrm{~min}$ at $880^{\circ} \mathrm{C}$, followed by quenching in oil, then tempering was then carried out at $520^{\circ} \mathrm{C}$ for $40 \mathrm{~min}$; the other was heated at $880^{\circ} \mathrm{C}$ for $40 \mathrm{~min}$, and then treated by AC. The chemical composition of this medium carbon steel is listed in Table 1. The microstructures of specimens were investigated using a Nikon Epiphot 220 optical microscope and a Hitachi S-3500 N scanning electron microscope (SEM).

The specimens for the $\mathrm{S}-\mathrm{N}$ fatigue experiments and FCG tests were manufactured to obtain the geometries illustrated in Figures 1 and 2, respectively. Before the tests, the surfaces of all the fatigue specimens were polished in the axial direction using No. 2000 abrasive paper. The S-N fatigue tests were conducted using a 50-kN MTS machine under a stress-controlled mode with a stress ratio $\mathrm{R}$ of -1 ; the FCG tests were conducted under load control on a 100-kN MTS servo-hydraulic testing machine with the same frequency $(10 \mathrm{~Hz})$. Specially, pre-cracks with a diameter of $2 \mathrm{~mm}$ and length of $2.5 \mathrm{~mm}$ were made at the notch tip of the specimens with a maximum force of $26 \mathrm{kN}$. The crack length was monitored by Microscope visual method, and the $\mathrm{da} / \mathrm{dN}-\Delta \mathrm{K}$ diagrams were calculated by secant method. Then, the dynamical mechanical analyser (DMA, model Q800, TA instrument Co., Ltd.) was used to measure the temperature and strain-dependent damping behaviours with a similar cyclic load in a single cantilever mode, where rectangle shaped specimens with a length of $35 \mathrm{~mm}$ and cross-section of $4 \times 1 \mathrm{~mm}^{2}$ were prepared.

\section{3 | RESULTS AND DISCUSSION}

\section{1 | Microstructures}

Figure 3 shows the optical and SEM micrographs of the 30CrMnSiA steels after AC and QT treatment, respectively. It is noted that the microstructures of AC steel is composed of white polygonal ferrite and dark pearlite from Figure 3A. The pearlite can be viewed as a lamellar structure composed of alternating layers of ferrite and cementite, which can be observed in Figure 3B. The average interlamellar spacing is about several hundreds of nanometres. The microstructure of the QT steel appears to be more homogeneous than that of the AC steel, as shown in Figure 3C. As can be seen from the Figure 3D, it is noted that the microstructures of QT steel are considered as the white cementite particles with dozens of nanometres distributed in a black ferrite matrix. This is because that the pearlite transforms to austenite firstly at $880^{\circ} \mathrm{C}$, and then the austenite subjects to a fast cooling (quenching) and transforms to martensite, after that the cementite particle is precipitated when temped at $520^{\circ} \mathrm{C}^{17}$ The cementite particles are uniformly distributed in the ferrite matrix and are proved to be play a significant role on dispersion strengthening. Cementite 
TA B L E 1 The chemical composition of 30CrMnSiA (wt $\%$ )

$\begin{array}{llllllllllll}\mathbf{C} & \mathbf{S i} & \mathbf{M n} & \mathbf{P} & \mathbf{S} & \mathbf{C r} & \mathbf{M o} & \mathbf{T i} & \mathbf{V} & \mathbf{W} & \mathbf{C u} & \mathbf{N i} \\ 0.305 & 1.08 & 1.00 & 0.017 & 0.003 & 0.99 & 0.001 & 0.004 & 0.007 & 0.002 & 0.013 & 0.012\end{array}$

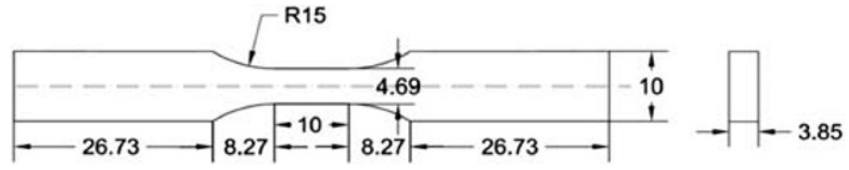

F I G U RE 1 Dimensions (in mm) of the specimens for tensioncompression fatigue tests

particles also have the advantage of a good combination with the ferrite matrix, which may be difficult to crack along the interface during cyclic loading.

\section{2 | Mechanical properties}

The tensile tests of the $30 \mathrm{CrMnSiA}$ samples were carried out at room temperature. The mean values of the mechanical properties with three specimens for each group is listed in Table 2. In addition, the S-N curves of both the AC and QT steels after fatigue experiments are presented in Figure 4. Because the fatigue result is always characterized by physiological scattering, the experimental data must be carefully post-processed to determine a reliable reference fatigue curve. ${ }^{18}$ Figure 4 presents three different straight trend lines, which correspond to three different values of the probability of survival, Ps (i.e. Ps $=5 \%$, Ps $=50 \%$ and Ps $=95 \%$ ). The scatter bands are also plotted in Figure 4, which are calculated by taking the confidence level equal to $95 \%$ and assuming a lognormal distribution of the number of cycles to failure for each stress level. The endurance limits (at $5 \times 10^{5}$ cycles to failure) of the AC and QT steels are found to be about 310 and $400 \mathrm{MPa}$, respectively. For the same fatigue life, the QT steel specimen endured higher stress amplitude than the AC steel specimen. Table 3 shows the scatter index referred to a probability of survival in the range of $5 \%-95 \%$ with the amplitude of the nominal gross stress, where the $\sigma_{\mathrm{A}}$ value of the AC steel was about $75 \mathrm{MPa}$ less than that of the QT steel. Stress-based scatter index (T) of the endurance limit range for PS $=95 \%$ and $\mathrm{PS}=5 \%$ is a
F I G URE 2 Dimensions (in mm) of the middle cracked tension (MT) specimens for fatigue crack growth (FCG) tests
F I G URE 3 Optical and scanning electron microscope (SEM) images of the microstructures of the (A), (C) AC and (B), (D) QT steels
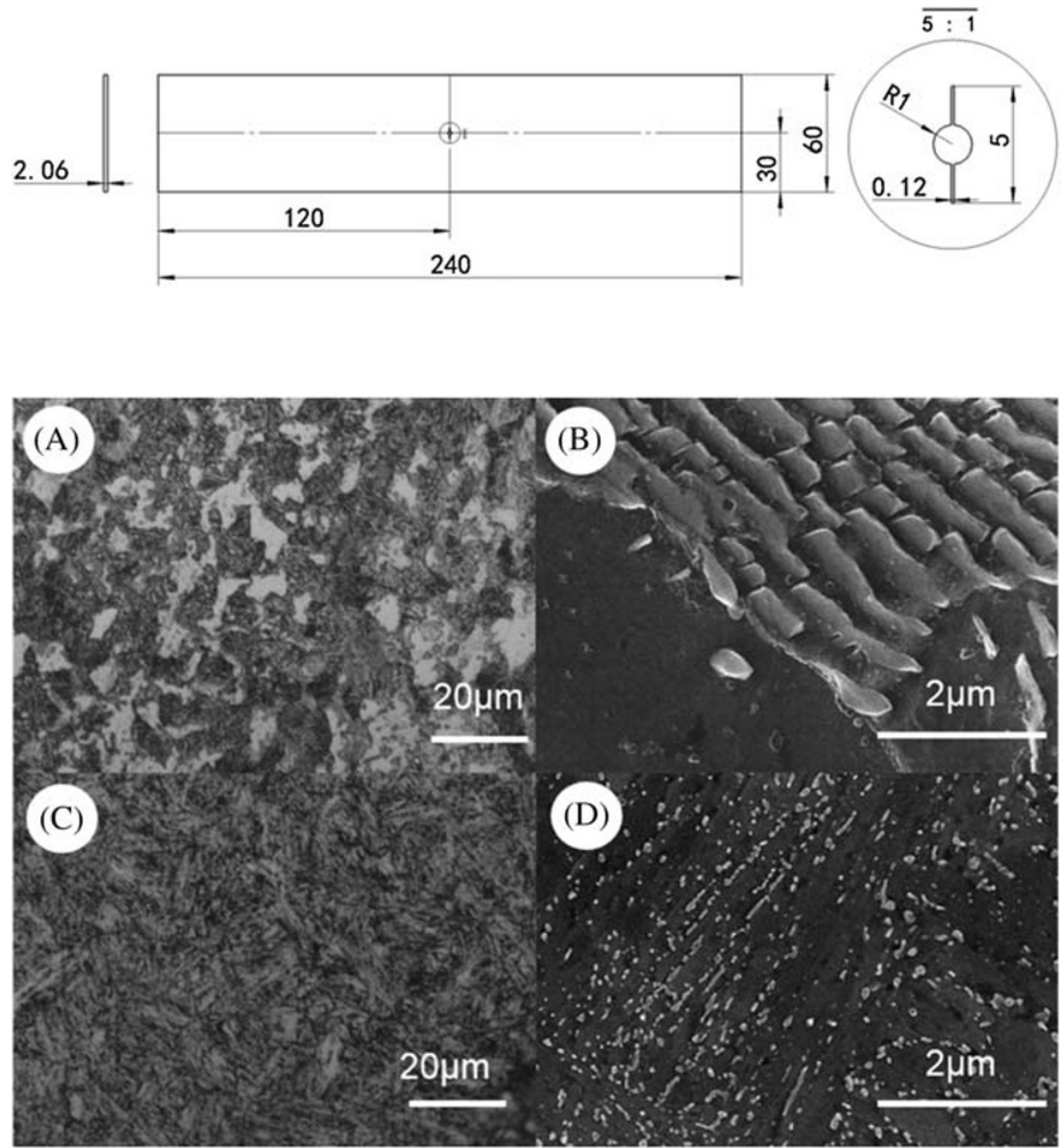
TABLE 2 The tensile properties of AC and QT steels

\begin{tabular}{lll} 
& \multicolumn{2}{l}{ Measure values } \\
\cline { 2 - 3 } Properties & AC steel & QT steel \\
\hline $\mathrm{E}(\mathrm{MPa})$ & 180004 & 189855 \\
$\sigma_{\mathrm{s}}(\mathrm{MPa})$ & 404 & 960 \\
\hline$\sigma_{\mathrm{t}}(\mathrm{MPa})$ & 675 & 1054 \\
$\varepsilon(\%)$ & 25.70 & 16.41 \\
\hline
\end{tabular}

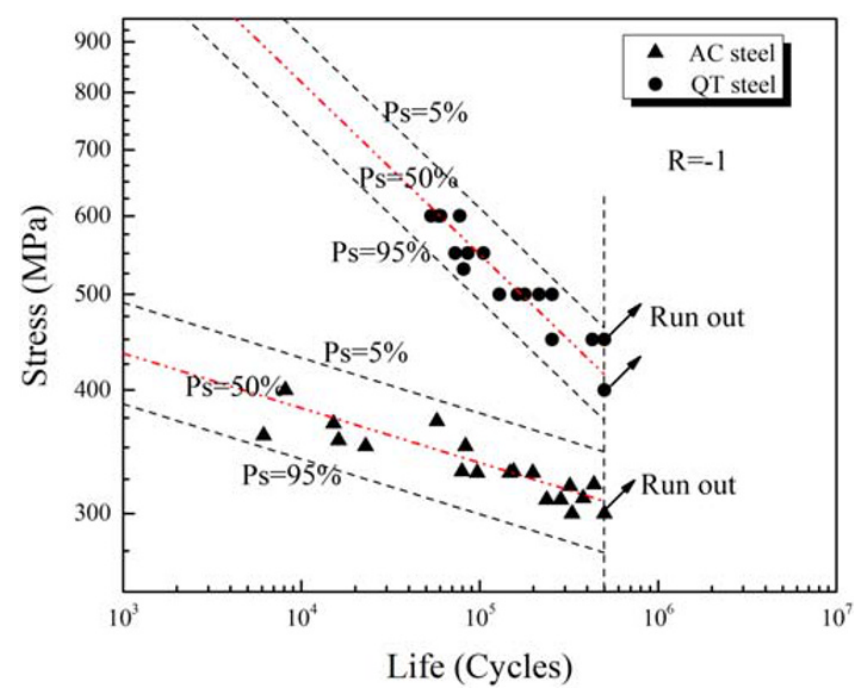

FI G U RE 4 Comparison of S-N curves of the AC and QT steels [Colour figure can be viewed at wileyonlinelibrary.com]

T A B LE 3 Detailed data of S-N curves of the AC and QT steels

\begin{tabular}{llllll} 
& \multicolumn{2}{c}{} & & \\
\cline { 2 - 4 } Material & $\boldsymbol{\sigma}_{\mathbf{A}, \mathbf{5 0} \%}(\mathbf{M P a})$ & $\boldsymbol{\sigma}_{\mathbf{A}, \mathbf{9 5} \%}$ & $\boldsymbol{\sigma}_{\mathbf{A}, \mathbf{5 \%}}$ & $\mathbf{T}$ & $\mathbf{K}$ \\
AC steel & 296.51 & 263.49 & 333.66 & 1.23 & 17.94 \\
QT steel & 367.18 & 329.45 & 409.24 & 1.18 & 5.75 \\
\hline
\end{tabular}

useful parameter for evaluating the level of scattering associated with a population of fatigue data. It is noted that the value of $\mathrm{T}$ in $\mathrm{AC}$ steel is about 1.23, whereas the one in QT steel is close to 1.18. This indicates that the QT steel has lower fatigue life dispersibility than the AC steel.

\section{3 | FCG rate and fracture surface}

To investigate the difference in fatigue behaviours between the AC and QT steels, the curves of FCG rate versus the applied stress intensity factor range are presented in Figure 5, in which the stress ratio $(R)$ is equal to previous $\mathrm{S}-\mathrm{N}$ fatigue tests $(R=-1)$. As can be seen from
Figure 5, three parts were divided in da/dN- $\Delta \mathrm{K}$ : the nearthreshold regime, the Paris regime and the final fracture regime. The microstructure has significant influence on FCG behaviour in near-threshold and final fracture regime, which is in accordance with previous studies. ${ }^{6,19}$ The AC steel behaves a lower growth rate when compared with the QT steel in the near-threshold regime. Actually, the fatigue fracture may initial from the slip zones adjacent to the outer or at internal voids or inclusions in materials. Only few cracks can propagate further when the stress concentration is high enough. It is noted that the $\mathrm{da} / \mathrm{dN}$ of QT steel in the near-threshold regime is slightly greater than that of $\mathrm{AC}$ steel at the same $\Delta \mathrm{K}$. This is because the low crack driving force may lead to a uniform crack front in AC steel; therefore, the crack becomes more tortuous or irregular. ${ }^{4}$ Then, a cumulative plastic strain between slip planes blunts the crack tip. ${ }^{20}$ However, the FCG rate of QT steel keeps a stable slope range with the increased $\Delta \mathrm{K}$ until $50 \mathrm{MPa} \cdot \mathrm{m}^{1 / 2}$, which is much larger than the one in AC steel (the critical value is about $37 \mathrm{MPa}^{1 / 2}$ ). That means the QT steel exhibits significantly higher FCG resistance in the Paris regime when compared with the AC steel. In my opinion, the precipitated cementite particles may play an important role on resisting the crack growth in Paris regime. The uniformly distributed cementite particles would induce higher plastic constrain because it is more difficult to be plastically deformed. Finally, dynamic crack propagation may complete the failure process because the stress intensity factor is equal to the critical stress intensity factor. It is noted the crack growth increase rapidly in both the QT and AC steels in final fracture regime and give rise to the catastrophic failure. We believe that the fatigue

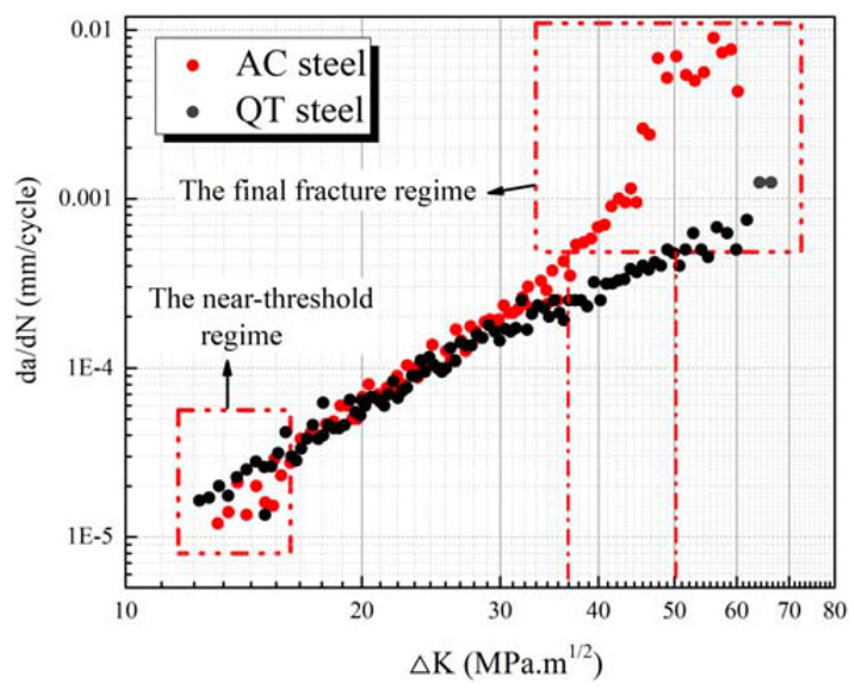

FI G U RE 5 Comparison of fatigue crack growth (FCG) curves for the AC and QT steel [Colour figure can be viewed at wileyonlinelibrary.com] 
F I G URE 6 Fracture morphology of the AC steel at different regimes: (A) the nearthreshold regime $\Delta \mathrm{K}=12 \sim 18 \mathrm{MPa}^{1 / 2}$; (B) the Paris regime $\Delta \mathrm{K}=18 \sim 37 \mathrm{MPa} \cdot \mathrm{m}^{1 / 2}$; (C) the final fracture regime $\Delta \mathrm{K}=37 \sim 60 \mathrm{MPa}$. $\mathrm{m}^{1 / 2}$. The white arrows indicate the direction of macroscopic crack growth

F I G URE 7 Fracture morphology of the QT steel at different regions: (A) the near-threshold regime $\Delta \mathrm{K}=12 \sim 18 \mathrm{MPa}^{1 / 2}$; (B) the Paris regime $\Delta \mathrm{K}=18 \sim 50 \mathrm{MPa} \cdot \mathrm{m}^{1 / 2}$; (C) the final fracture regime $\Delta \mathrm{K}=50 \sim 60 \mathrm{MPa}$. $\mathrm{m}^{1 / 2}$. The white arrows indicate the direction of macroscopic crack growth
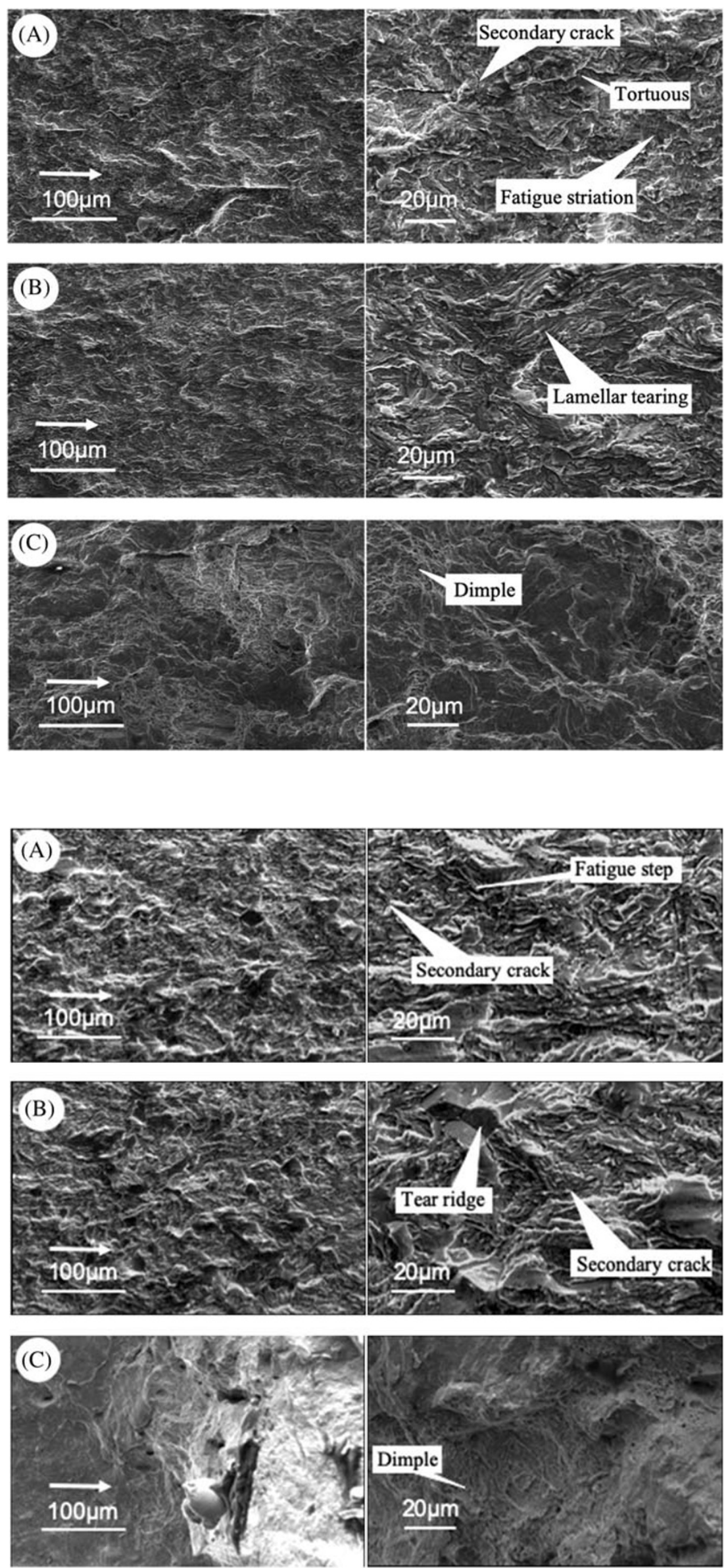
crack in the QT steel is more difficult to propagate in Paris regime owing the appearance of the precipitated hard particles, which in turn results in a higher fatigue life.

To more clearly determine the fatigue mechanism of the AC and QT steels, the fatigue fractures of the specimens were observed via SEM under similar cyclic loading conditions. Figures 6 and 7 show, respectively, the surfaces of the AC and QT steels at different fracture regions. As shown in Figure 6A, the region of near-threshold crack growth in the AC steel exhibits a typical ductile fracture, where striations, tortuous features and secondary micro-cracks can be observed. In contrast, as shown in Figure 7A, significant fatigue steps appear in the QT steel. Fatigue steps can be viewed as convincing evidence that the cracks leapt forward between the cleavage planes. ${ }^{19,21}$ It is also a significant gauge by which to measure the resistance of cracks when the second hard phase blocks crack propagation. ${ }^{6-10}$ With the increase of $\Delta \mathrm{K}$, both the AC and QT steels reached the steadily extending stage. As shown in Figures $6 \mathrm{~B}$ and $7 \mathrm{~B}$, the fractographies of the $\mathrm{AC}$ steel are smoother than those of QT steel. Lamellar tearing of ferrite-pearlite microstructure is observed in the AC steel, which can be viewed as the typical fatigue fracture feature. However, the tear ridge and secondary crack appear in QT steel which correspond to the quasi-cleavage fracture mode. In addition, the trend of crack growth has a certain directivity in AC steel because the deformation mainly occurred in ferrite, and the fatigue cracks tend to start along the ferrite-pearlite boundary., ${ }^{43,22}$ However, the appearance of fatigue step in QT steel has no preferred orientation. This is because the cementite particles had a dense and random distribution in the QT steel, which could effectively resist crack propagation. This is also consistent with the results that the QT steel has a much broader Paris region, as shown in Figure 5. As can be seen from Figures $6 \mathrm{C}$ and $7 \mathrm{C}$, the extension of crack growth final resulted in the catastrophic failure in which a large number of dimples can be observed.

\subsection{Dynamic mechanical analysis}

Generally, internal friction (IF) is a key indicator for the evaluation of the microstructure or defect evolution of metal systems during cyclic loading, ${ }^{23,24}$ particularly in $\mathrm{Fe}-\mathrm{C}$ systems. ${ }^{25}$ It is believed that the investigation of IF can reveal useful information about fatigue crack initiation and growth by determining the relationship between the dislocation pile-up and the pinning effect of spherical cementite particles. As we can see from
Figure 8, the energy storage modulus of QT steel and $\mathrm{AC}$ steel decreases with the increase of temperature or strain, however, the AC steel has a larger slope than QT steel in strain-dependent damping curve. The IF value of the QT steel increases moderately with the increased temperature as shown in Figure 8A. Nevertheless, an obvious Snoek peak around $20^{\circ} \mathrm{C}$ appears in AC steel, which may be associated with the uniformly distributed dissolved carbon in ferrite. ${ }^{22}$ Figure $8 \mathrm{~B}$ presents the strain amplitude-dependent IF behaviours. The IF of AC steel has an initial high growth rate with the increase of strain and then reaches a stable value. On the contrary, the QT steel exhibits a much smaller growth rate than the AC steel in lower strain amplitude. The IF growth tendency presented in Figure 8B shows good agreement with the FCG presented in Figure 5. Previous studies show that small amounts of strain can create new dislocations, which result in the prevalence of dislocation multiplication. Therefore, the increase of dislocation density may lead to a rapid increase in the IF value. QT treatment
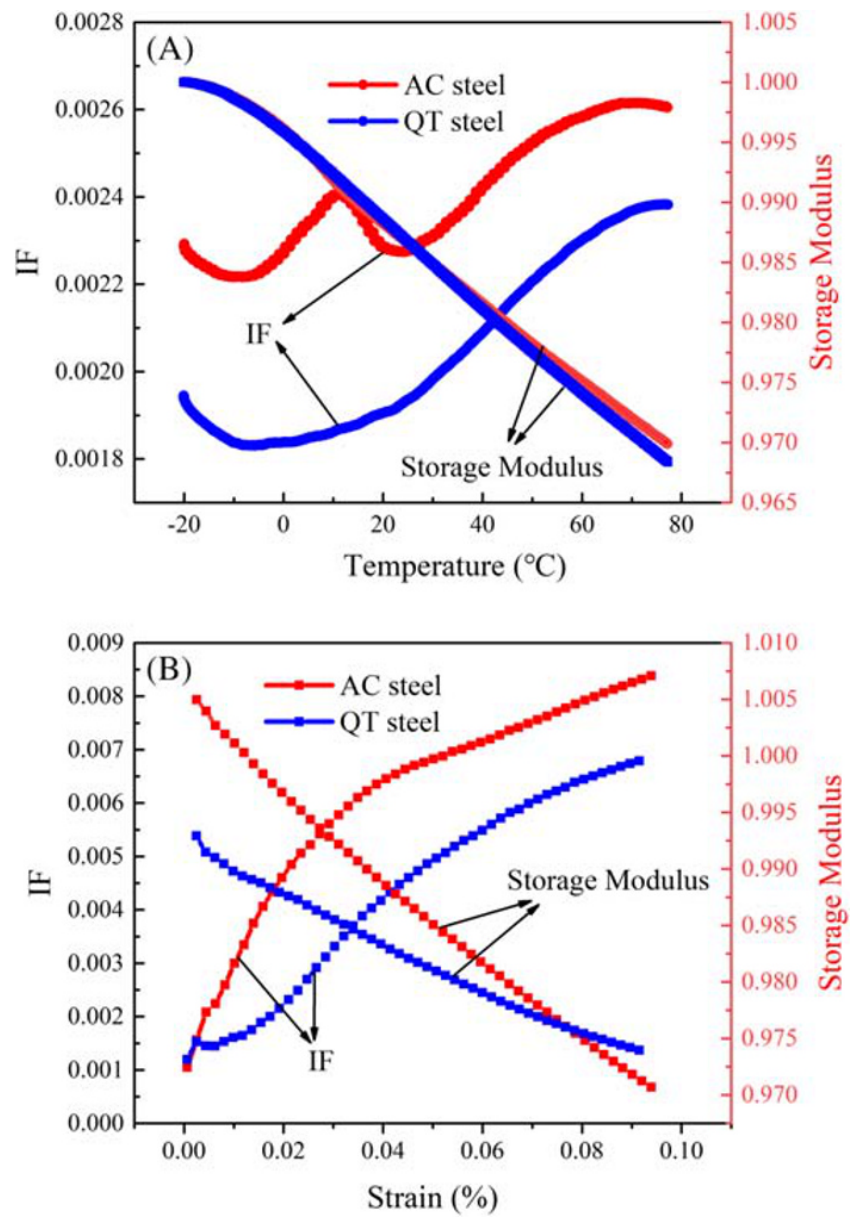

F I G U RE 8 (A) Comparison of temperature-dependent damping between the AC and QT steels. (B) Comparison of straindependent damping between the AC and QT steels [Colour figure can be viewed at wileyonlinelibrary.com] 
can cause a change of obstacles that impede dislocation oscillation by the formation of the cementite particles, which bring in a strong pinning effect. The lower IF value of the QT steel than of the AC steel can be explained based on the Granato-Lucke theory. ${ }^{26}$ The results are also in accordance with the fracture features. A lower IF value indicates that it is more difficult for dislocation to escape from the atmospheres of pinning obstacles. That is why a quasi-cleavage fracture mode accompanied by the rough fracture morphology of QT steel during cyclic loading can be obtained.

\section{4 | CONCLUSIONS}

The present investigation was carried out to study the effects of different microstructures on the fatigue properties in $30 \mathrm{CrMnSiA}$ steel. The stress fatigue experiments and FCG tests were carried out, respectively. The facture mechanism during cyclic loading was investigated via DMA. The main conclusions can be summarized as follows.

- The QT steel behaves a higher fatigue strength and lower fatigue life dispersibility than the AC steel. In addition, the AC steel behaves a lower growth rate when compared with the QT steel in the near-threshold regime. However, the FCG rate of QT steel keeps a stable slope range with the increased $\Delta \mathrm{K}$ until $50 \mathrm{MPa} \cdot \mathrm{m}^{1 / 2}$, which is much larger than the one in AC steel.

- The fracture surface of the AC steel shows a ductile fracture, whereas the QT steel exhibits a quasi-cleavage fracture mode. The precipitated cementite particles represent a strong pinning effect on both the FCG and strain-dependent damping rate.

\section{ACKNOWLEDGEMENTS}

The authors would like to acknowledge the financial supports from the National Natural Science Foundation of China (Grant 51401028, 51271193, 11402277 and 11790292) and the Strategic Priority Research Program of the Chinese Academy of Sciences (Grant XDB22040303). This work was also supported by the Innovation Program (237099000000170004).

\section{NOMENCLATURE}

$\sigma_{\mathrm{s}} \quad$ Yield strength

$\sigma_{\mathrm{t}} \quad$ Ultimate tensile strength

$\sigma_{\mathrm{A}} \quad$ Amplitude of the nominal gross stress at $1 \times 10^{6}$ cycle

E Young's modulus

$\varepsilon \quad$ Elongation

$\mathrm{T} \quad$ Stress-based scatter index

$\mathrm{K}$ Negative inverse slope of the Wohler curve
Ps The values of the probability of survival

$\Delta \mathrm{K}$ Stress intensity factor range

$\mathrm{R}$ The stress ratio

FCG Fatigue crack growth

AC Air cooling

QT Quenching and tempering

\section{ORCID}

Zheng Hu (1) https://orcid.org/0000-0001-7419-4993

Luca Susmel (1) https://orcid.org/0000-0001-7753-9176

Kun Zhang (1) https://orcid.org/0000-0003-0997-0428

Yang Wang (i) https://orcid.org/0000-0001-9877-0182

\section{REFERENCES}

1. Li YX, Lin ZQ, Jiang AQ, Chen GL. Use of high strength steel sheet for lightweight and crashworthy car body. Mater Design. 2003;24(3):177-182.

2. Nie WJ, Wang XM, Wu SJ, Guan HL, Shang CJ. Stress-strain behavior of multi-phase high performance structural steel. Sci China Technol Sc. 2012;55(7):1791-1796.

3. Sun XJ, Li ZD, Yong QL, Yang ZG, Dong H, Weng YQ. Third generation high strength low alloy steels with improved toughness. Sci China Technol Sc. 2012;55(7):1797-1805.

4. Guan MF, Yu H. In-situ investigation on the fatigue crack propagation behavior in ferrite-pearlite and dual-phase ferrite-bainite low carbon steels. Sci China Technol Sc. 2013; 56(1):71-79.

5. Hu Z, Li HY, Bu SF, Yang LL, Han M, Ning KY. The effect of controlled shot peening on the microstructure and fatigue behavior of wet copper-based powder metallurgy friction plates. Mater Res-Ibero-am J. 2018;21(4):1-7.

6. Sankaran S, Sarma VS, Padmanabhan KA, Jaeger G, Koethe A. High cycle fatigue behaviour of a multiphase microalloyed medium carbon steel: a comparison between ferrite-pearlite and tempered martensite microstructures. Mat Sci Eng a-Struct. 2003;362(1-2):249-256.

7. Nomura I. Influences of microstructures of fatigue strength of medium carbon microalloyed steels. Tetsu to Hagane. 1997; 83(3):227-232.

8. Yaguchi H, Tsuchida T, Matsushima Y, Abe S, Iwasaki K, Inada A. Effect of microstructures on the fatigue behavior of $\mathrm{V}$ added ferrite-pearlite type microalloyed steels. Kobelco Technology Review (Japan). 2002;25:49-53.

9. Cha XQ, Hui WL, Yong QL. High-cycle fatigue fracture behavior of ferrite-pearlite type microalloyed steels. Chinese J Mater Res. 2009;22:634-638.

10. Hui WJ, Dong H, Weng YQ. High-cycle fatigue properties of medium-carbon microalloyed forging steels. Iron Steel/Gangtie. 2011;46:1-6.

11. Kwon H, Barlat F, Lee M, Chung Y, Uhm S. Influence of tempering temperature on low cycle fatigue of high strength steel. Isij Int. 2014;54(4):979-984.

12. Hajisafari $M$, Nategh $S$, Yoozbashizadeh $H$, Ekrami A. Fatigue properties of heat-treated 30MSV6 vanadium microalloyed steel. J Mater Eng Perform. 2013;22(3):830-839.

13. Igwemezie V, Dirisu P, Mehmanparast A. Critical assessment of the fatigue crack growth rate sensitivity to material 
microstructure in ferrite-pearlite steels in air and marine environment. Mat Sci Eng a-Struct. 2019;754:750-765.

14. Rawal S, Gurland J. Observations on the effect of cementite particles on the fracture toughness of spheroidized carbon steels. Metall Trans a. 1977;8(5):691-698.

15. Feng XQ, Yu SW. Damage micromechanics for constitutive relations and failure of microcracked quasi-brittle materials. Int J Damage Mech. 2010;19(8):911-948.

16. Hong YS, Sun CQ. The nature and the mechanism of crack initiation and early growth for very-high-cycle fatigue of metallic materials - an overview. Theor Appl Fract Mec. 2017;92: 331-350.

17. Thelning K-E. Steel and Its Heat Treatment. UK: Butterworthheinemann; 2013.

18. Hu Z, Berto F, Hong YS, Susmel L. Comparison of TCD and SED methods in fatigue lifetime assessment. Int $J$ Fatigue. 2019;123:105-134.

19. Chan KS. Scaling laws for fatigue crack. Metall Trans a. 1993; 24(11):2473-2486.

20. Shyam A, Lara-Curzio E. A model for the formation of fatigue striations and its relationship with small fatigue crack growth in an aluminum alloy. Int J Fatigue. 2010;32(11):1843-1852.

21. Guan M, Yu H. Fatigue crack growth behaviors in hot-rolled low carbon steels: a comparison between ferrite-pearlite and ferrite-bainite microstructures. Mat Sci Eng a-Struc. 2013;559: 875-881.

22. Hui WJ, Chen SL, Zhang YJ, Shao CW, Dong H. Effect of vanadium on the high-cycle fatigue fracture properties of mediumcarbon microalloyed steel for fracture splitting connecting rod. Mater Design. 2015;66:227-234.

23. Blanter MS, Golovin IS, Neuhauser H, Sinning H. Internal friction in metallic materials. A Handbook. 2007;540:1-144.

24. Rao DL, Xu ZQ. Damping behavior of 304L stainless steel after fatigue loading. Theor Appl Fract Mec. 2019;100:110-113.

25. Saitoh $\mathrm{H}$, Ushioda $\mathrm{K}$. Influence of substitutional atoms on the Snoek peak of carbon in BCC iron. Acta Mater. 2004;52(5): 1255-1261.

26. Granato A, Lucke K. Theory of mechanical damping due to dislocations. J Appl Phys. 1956;27(6):583-593.

How to cite this article: Zhang Y, Hu Z, Susmel L, et al. Fatigue behaviour of a multiphase medium carbon steel: Comparison between ferrite/ pearlite and tempered microstructures. Fatigue Fract Eng Mater Struct. 2020;1-8. https://doi.org/ 10.1111/ffe.13274 